
3 Research Square
Preprints are preliminary reports that have not undergone peer review.
They should not be considered conclusive, used to inform clinical practice,
or referenced by the media as validated information.

\title{
Family-centered approach to monitoring children's development in a paediatric outpatient setting: feasibility study from Pakistan
}

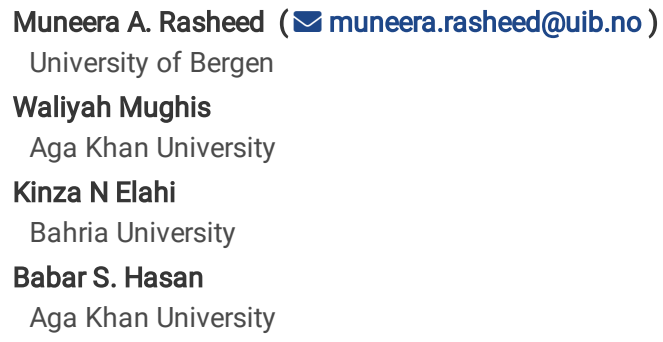

\section{Research Article}

Keywords: Care for Child Development module, developmental monitoring, family-centered support, nurturing care, paediatric outpatient, Survey of Well-being of Young Children

Posted Date: March 26th, 2021

DOI: https://doi.org/10.21203/rs.3.rs-194080/v3

License: @ (i) This work is licensed under a Creative Commons Attribution 4.0 International License. Read Full License 


\section{Abstract}

Background: The purpose of the study was to design and test the feasibility of a recent guideline of family-centered psychosocial support as an approach to developmental monitoring in a pediatric outpatient setting.

Methods: The patient experience team at a private tertiary care hospital leveraged an on-going patient and family-centric initiative in the service to implement the intervention. The intervention delivery model was designed using the theory of change model and entailed the following i) the service providers: paediatricians but with support from psychology trainee volunteers to address time constraints; ii) monitoring form: Survey of Well-Being of Young Children (SWYC) being feasible and designed for regular developmental monitoring as parent report; iii) family support intervention: the Care for Child Development module to enhance parent-child interactions given team's successful experience with inpatient children; iv) timing: utilize wait time to also enhance families' experience and v) reinforcement: reinforced by the paediatrician in the consultation visit to capitalize on the established rapport and relationship with families. All families with children under 5 years 5 months of age in selected clinics (acute care, complex care, developmental issues) were eligible. The study was evaluated for acceptability and implementation feasibility. Families were interviewed about their experience; trainees provided a written narrative while physicians provided feedback on email. These were thematically analyzed using an inductive approach.

Results: A total 182 families were administered the SWYC with $54 \%$ children detected for further review on cognitive milestones and $76 \%$ on social-emotional milestones. Forty-eight families were interviewed regarding their experience with the intervention. They reported the monitoring process to be useful and important for them as parents indicating acceptability. Paediatricians and trainees found the intervention to be important for parents and children's health also requesting further understanding about child's functioning. The trainees further expressed the experience to be significant for their own learning.

Conclusion: The authors conclude that the intervention model for a family-centric approach to monitoring was acceptable to the families and the service providers. The intervention when implemented using a robust behaviour change framework can enhance feasibility.

\section{Contribution To The Literature}

- Developmental monitoring followed by family-centered psychosocial support in primary care service has been recommended by the World Health Organization as the first step to build comprehensive services for children at risk of developmental disability.

- Feasible integration of such interventions in an existing healthcare system requires that delivery models be informed by a robust theoretical framework of behaviour change.

- In a relatively small sample this study indicated acceptability and feasibility of the intervention by the families and service providers when designed using a theory of change model.

\section{Introduction}

In low-and-middle-income countries (LMICs) globally, nearly 250 million children are not meeting their potential [1] with 1 in 6 experiencing developmental difficulty [2]. Developmental monitoring for adequate referral requires continued efforts for integration in healthcare in the LMIC context [3,4] while it is considered an integral practice in high income settings, such as the USA. American Academy of Pediatrics recommends developmental screening to be completed at least at 9, 18 and 30 months of age during a child's critical developmental period [5]. A recent report of a technical meeting by the World Health Organization recommended broadening the scope of developmental monitoring to also include family-centered participatory support interventions ensuring nurturing care for all [6]. The experts have argued that these guidelines place the primary care providers in a unique position to promote children's development given their relationship with the family and being aware of the specific strengths and vulnerabilities built on regular contacts [7].

Pakistan is a nation with substantial burden of children at risk for not attaining their potential with high rates of maternal mortality (140/100,000), under-five mortality (69/1000) and stunting (38\%) [8]. Moreover, no data on provision of nurturing care practices at home is available. Sustainable integration of nurturing care into primary healthcare will require partnerships not just between family and provider or between different providers but also broadly within and across sectors like health and education $[9,10]$. Private providers are an important partner to tap into especially in contexts where they are the major contributors [11]. In Pakistan, only $2.8 \%$ of the country's budget is annually invested in healthcare, which is globally one of the lowest [12] and the private sector covers up to $75 \%$ of the population's healthcare $[13,14]$.

A study from Pakistan in private outpatient clinics with mothers of young children found that counseling focused on promoting development were more engaging and helpful than the usual/standard care provided by paediatric consultants [15]. However, the programme was funded through a research grant and scale-up of the innovation will likely remain dependent on philanthropy for further implementation. Given the financial adversity currently in the country, is not a sustainable option. Long-run integration of family support practices within paediatric care to transform development of millions of children requires context-specific and cost-effective approach similar to social innovations taking into account not just technical feasibility but also market sustainability and economic viability of the population to ensure uptake [16]. Examples of social innovations from similar contexts like India operate on these principles for a successful scale-up: designing interventions with a value for more rather than a perfectly designed model serving a few, utilizing and strengthening existing systems for reduced costs and ensuring respect and experience of the families served [17]. Additionally, literature from implementation sciences strongly suggests the use of a robust framework like Theory of Change $(\mathrm{ToC})$ to design complex behaviour change interventions involving multiple touch-points and 
actors [18]. The ToC methodology outlines how the intervention will work in real settings, describing the processes through which the change will happen and the assumptions inherent but specific to the context [19]. WHO recommendations for a family-centered intervention will require further guidelines on operationalization in primary care. Use of ToC to implement these guidelines following the principles of social innovation has not been tested yet. The objective of this study was to develop and test the feasibility of integrating developmental monitoring as a family-centered support in a private paediatric care setting in Pakistan.

\section{Methods}

\section{Setting}

The study was conducted at Aga Khan University Hospital, a tertiary care teaching hospital and Joint Commission International accredited hospital (JCIA) in Karachi, Pakistan. Annually about 75,000 out-patients visit the pediatric outpatients' clinics. Well-baby clinics are conducted within Paediatrics, but developmental monitoring is yet to be established in the system. The fee structure of AKUH is comparable to other private tertiary health centers within the city. Patients are primarily from Karachi and surrounding urban and rural areas within the province of Sindh.

One of the few studies conducted on parental stress of those with children with intellectual and physical disabilities found that parental anxiety and depression increases significantly with the child's severity of disability [20]. Barriers such as social stigma and cultural norms, inadequate health infrastructure and shortage of qualified professionals in ECD prevent parents from seeking appropriate timely support for their differently abled child [21]. The implementation of the World Health Organization Global Disability Action Plan in Pakistan (GDAP) requires engagement of healthcare professionals and public-private institutional partnerships in order to provide appropriate awareness and rehabilitative access to patients and parents with ECD needs [22].

\section{Workflow}

In the outpatient clinic at AKUH, patients book their appointments online or by calling the hospital helpline. Patients are expected to arrive and register and pay the consultation fee 20 minutes prior to the appointment time. Next, the child/parents are then called into the assessment room where a nurse records, in the patient file, the child's height, weight, temperature, blood pressure, risk of fall, known allergies, and any prescribed medications. The patient file is shifted to the file tray outside the physician's consulting room and parents/families are then requested to be seated in the waiting area until they are called to meet with the consultant. Average time spent in the clinic from start to finish ranges from 75 to 120 minutes. Waiting time varies from between physicians, ranging from 40 to 80 minutes. No toys, play equipment or books are currently available in the waiting area for children and their parents to utilize during long waiting times. One physician on average may see up to 112 patients per month (ranging from 55 to 235 patients monthly per physician, depending on specialty).

\section{Research Design}

This feasibility study [23] was conducted as quality improvement project [24] in the paediatric service line at the AKUH for improved patient and family experience of care. The primary considerations of feasibility were physical space/design, human and material resources, and physician follow-up with patients identified to be at developmental risk.

\section{Sample}

The inclusion criteria comprised all the children (patients) who visited the ten selected physicians in AKUH outpatient department (OPD) and age range: birth to $5 \frac{1}{2}$ years. The physicians were selected to cover a broad range of disease: acute care (6 out of 18 general pediatricians at AKUH), complex care ( 3 of 6 pediatric cardiologists at $\mathrm{AKUH}$ ) and developmental care (one of 2 specialists at AKUH). Prior permission from physicians was sought to complete developmental screening with their patients. Permission was obtained from the 10 physicians to conduct research with their patients. The parents of the patients were briefed about the purpose of the survey and verbal consent was obtained before being then interviewed. The study was approved as a quality improvement project by the AKU Ethics Review Committee.

\section{Intervention design}

The implementation opportunity was identified by an Early Childhood Development (ECD) specialist in the service line and also serving as the Director Patient Experience. The study was conducted between August 2019 and February 2020 as part of the overall patient and family centric initiative that was in place since October 2017. The aim of the initiative was to create a culture that valued patient and family experience with the service [25]. The intervention model was designed using the Theory of Change (ToC) guided by the following principles at micro-level: ensure value addition for all stakeholders, leverage existing strengths, keep it simple and cost-effective yet comfortable while being grounded in science at the same time. The ToC was developed after thoughtful considerations by the patient experience team about how the intervention would work in the context [Figure 1].

The context was analyzed based on the team's observation and experience for assumptions around different intervention components.

Delivery staff: The country has a handful of developmental paediatricians [26] with few training opportunities in residency programmes [27] suggesting the urgency of initiating intervention models with opportunities to refine iteratively during implementation. The limited supply of professionals qualified in ECD is 
reflective of the low demand from parents of young children to monitor development. Such non-medical services are not usually valued enough for families to pay additionally for them would be seen as burdensome by most families and would result in low uptake if a service were initiated in silo [28]. Developmental screening though important is not done routinely as not enough demand has been created. Hence, it is not seen as value by patients and physicians (who don't see it generating revenue) [29]. Making this part of the regular clinic would mean identifying an additional cadre. The cadre was identified to be psychology trainees from a local university AKU had a memorandum of understanding with. This will give the paediatrician additional, important information that adds value to that clinic visit at no cost to the practice. The service can be then feasibly integrated by the paediatrician. The recommendations for followup for parents when reinforced by the paediatrician who are seen to be more trustworthy by families can enhance families' trust in the process [30]. Thus, creating value around child development and may increase engagement and parental ownership.

The family support intervention: The psychosocial support intervention was based on principles of the Care for Child Development (CCD) module [37]. The module includes messages to enhance nurturing parent-child interaction using play activities. The first author was a certified trained for implementing the $C C D$ module and had successfully led the intervention for in-patient children and families in collaboration with psychology trainees as the lead delivery staff [38].

The final delivery model included: 1) the developmental monitoring from and support recommendation [SWYC] to be completed 2) by the psychology trainees 3) during wait time 4) followed by integration in the routine paediatrician follow-up, capitalizing on the rapport and relationship between parent and physician while leveraging the on-going patient and family-centric initiative in the service line [Table 1].

Table 1. Outcomes, assumptions, need assessment and interventions of the ToC model 


\begin{tabular}{|c|c|c|c|c|}
\hline Domain & Outcome & Assumptions & Needs assessment & Intervention \\
\hline $\begin{array}{l}\text { Reach \& } \\
\text { reaction: }\end{array}$ & $\begin{array}{l}\text { Eligible } \\
\text { children are } \\
\text { reached }\end{array}$ & $\begin{array}{l}\text { Families of young } \\
\text { children can be } \\
\text { reached through } \\
\text { trained staff. }\end{array}$ & $\begin{array}{l}\text { Paediatricians won't have enough time } \\
\text { in the clinic for developmental } \\
\text { monitoring form administration. } \\
\text { However, if the initial assessment is } \\
\text { supported by another cadre, } \\
\text { paediatricians can quide the families. }\end{array}$ & $\begin{array}{l}\text { Partner with a psychology university and use } \\
\text { psychology trainees. Provide training and clinical } \\
\text { supervision. }\end{array}$ \\
\hline $\begin{array}{l}\text { intervention } \\
\text { delivered } \\
\text { reach the } \\
\text { intended } \\
\text { target }\end{array}$ & & & $\begin{array}{l}\text { The additional cadre needs to have time } \\
\text { and relevant experience but cannot } \\
\text { burden the existing staff. }\end{array}$ & $\begin{array}{l}\text { A form which provides greater false positives is } \\
\text { preferable as no potential child and family in need is } \\
\text { missed for a conversation about promotion of } \\
\text { nurturing care. }\end{array}$ \\
\hline
\end{tabular}

groups with

the right

reaction?

There is a demand for monitoring services to promote children's development.
The country has a handful of developmental paediatricians with limited training opportunities in residency programmes. The limited supply of professionals qualified in ECD is reflective of the low demand from parents of young children to monitor development. Hence, service in silos for developmental advice will not result in significant uptake. The paediatricians would not be invested in spending additional time or training effort on developmental consultation without due reimbursement.

Utilize wait time for monitoring which is already a pain for the families. When wait times cannot be reduced, opportunities of utilizing it meaningfully to add value to overall experience can engage families. The service has to be free of cost to begin with. Personnel costs for psychology trainees can be reduced through training, clinical supervision and credit for internship hours to administer the form. However, has to be reinforced by the paediatrician capitalizing the trust and relationship. For the paediatricians it will be a value-add as they provided additional messaging on health functioning of the patient within the same fee.

Leverage the already in place 'The Patient and Family-Centric Initiative' which values nurturing experiences as one of the core processes of care. Moreover, it is also now being recognized in the system that ECD is a long-term health outcome.

There has been significant value creation for psychosocial needs during the 'The Patient and Family-Centric Initiative' for buy-in from physicians. Psychology clinic experience indicates families welcome discussion of emotional behaviour problems and greater acceptance when reinforced by the paediatrician.

Families and paediatricians will accept the intervention

$\begin{array}{llll}\begin{array}{l}\text { Capacity } \\ \text { change }\end{array} & \begin{array}{l}\text { Mothers } \\ \text { acquire new } \\ \text { capacity about } \\ \text { nurturing care } \\ \text { practices }\end{array} & \begin{array}{l}\text { The advice will be } \\ \text { understood and } \\ \text { mothers will } \\ \text { comply. }\end{array} & \begin{array}{l}\text { Approach has to be simple with focus } \\ \text { on milestones and also the } \\ \text { environment. Pediatricians at AKUH are } \\ \text { trusted as it is considered an elite } \\ \text { hospital in the city. }\end{array} \\ \text { Will the } & \text { n } & & \end{array}$

interventions
Use a simple checklist created for monitoring in the OPD with a focus on the role of environment. 
delivered

and

their reach

lead to the

intended

capacity

changes?
Mothers have the capability to seek new knowledge.

Mothers are motivated to improve the development of children
Families are generally from the middle class and educated.

The schools heavily emphasize

cognitive skills for entry which is a

factor that can be heavily leveraged for engagement.

Reinforcement from the paediatrician is needed with focus on long-term achievement in school.

$\begin{aligned} & \text { Behaviour } \\ & \text { change }\end{aligned}$
Will the
capacity
change lead
to the
intended
Behaviour
Changes?

\section{Parents} specifically mothers adopt new practices

\section{Mothers can make decisions about their child.}

Parents can observe improvement in child's development
Generally, fathers have a greater role in decision-making.

Generally parents lack knowledge of developmental milestones.
Paediatricians reinforce both parents for uptake.

Psychology trainees can provide guidance to parents for relevant websites or other sources for monitoring their children's development.

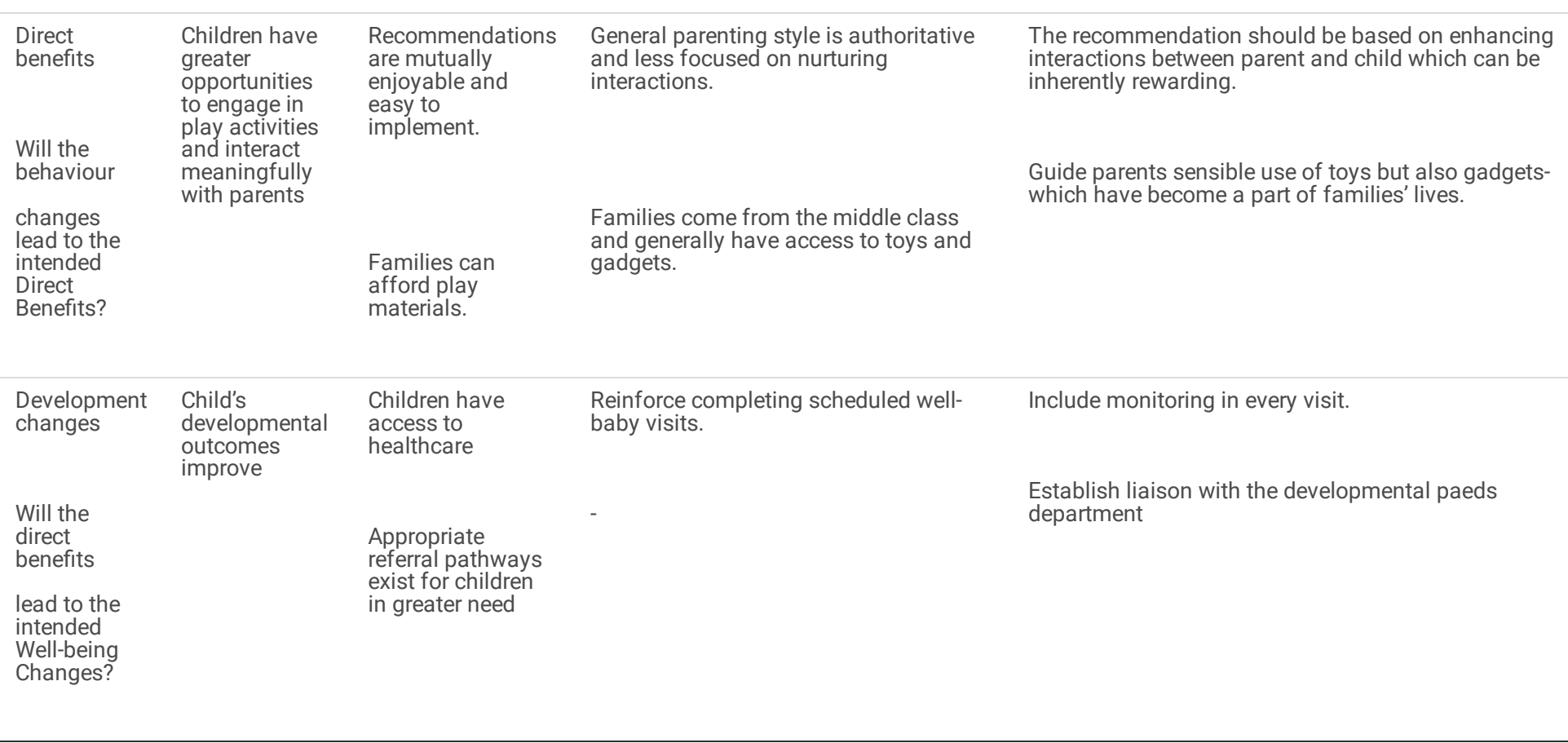

Note: The ToC was based on principles presented by Mayne J. Theory of change analysis: Building robust theories of change. Canadian Journal of Program Evaluation. 2017 Dec 4;32(2). https://doi.org/10.3138/cjpe.31122

\section{Intervention Procedure}

The developmental monitoring component was administered by four psychology trainees: two research associates (psychology graduates) having significant experience with assessment of children with developmental disabilities and two student trainees. Each student trainee was paired with an associate for quality assurance. As part of the procedure, the family was guided to see the trainee once the clinical assessment was completed by the nursing staff. The SWYC was completed during wait time. When a parent used to meet the trainee, language was chosen based on the family's preference, and trainees asked parents if they would like to fill the survey themselves or with the support of the trainee as an interviewer reading out the questions and tracking their responses for the parents. The raw scores on SWYC were calculated for developmental milestones checklist covering cognitive, motor \& language domains, emotional \& behavioural symptoms items and family stress. The scores were then classified as 'Appears to be meeting expectations' or 'Needs review' based on the SWYC guidelines. This description was entered on a summary form attached to the patient file to be seen by the paediatrician. Based on the SWYC summary form, the paediatrician provided advice and recommended referral if needed. About $15 \%$ of the forms were re-evaluated by the first author with the families. Feedback was thereafter given to the trainees for any clarification or elaboration. 


\section{Data Collection}

Data from the parents was collected through a feedback form administered after the SWYC by the trainee. The parental feedback form comprised of 6 questions, of which 2 were open-ended ("How did you feel before filling the form and after completing the [monitoring] session?" and "What did you like best about this mini-session?") and 4 close-ended questions ("Do you think understanding your child's developmental progress and emotional needs is required?", "Would you like to discuss the results of this form with your child's paediatrician?", "Would you like further information on ways to stimulate your child, such as a brochure with guidelines for activities for various age groups?" and "Have you ever visited a neurologist or psychologist before?" The trainees were requested to share their reflections as a qualitative narrative shedding light on their experiences and specific barriers and enablers. Physician feedback was obtained on email in response to findings shared with them about the developmental status of their patient population part of the study. The email was shared at two time points in the study: when one third of the sample was interviewed and when the study sample was completed. The data collection continued till the patient and family-centric initiative wad in place.

\section{Data Analysis}

The responses on the SWYC were scored based on the cut-off available with the form. Frequency and percentages were calculated for children indicated positive for further review by the paediatrician. Feasibility was evaluated for acceptability and implementation using the Bowen et al. (2009) framework [39]. Data was analyzed in SPSS V22.0 for cross-sectional descriptive statistics. Qualitative feedback from parental experience, physicians and trainee reflections were analyzed using thematic analysis for an understanding of their experience from their perspective. The analysis team included the ECD specialist and a developmental psychologist-who was independent of implementation. An inductive approach was employed for analyses following the standard procedures [40]. The responses were coded independently by the two team members for the qualitative data and then finalized in an agreement meeting. The codes were then broadly reduced under two aspects of feasibility: acceptability and implementation.

\section{Results}

A total of 182 families with 67 girls and 115 boys participated in the study. $70 \%$ of families preferred administration in English. Additionally, $30 \%$ preferred to fill the form themselves, and $70 \%$ asked the trainee to take the interview. The results indicate that $54 \%$ were detected positive on cognitive, physical and language milestones and $76 \%$ on emotional \& behavioral symptoms requiring further advice about nurturing care [Table 2]. Moreover, the trends indicated a greater number of positives in the developmental clinic as expected.

Table 2: Children identified for further review

\begin{tabular}{|c|c|c|c|c|}
\hline \multirow[t]{3}{*}{ Developmental Domain from SWYC } & \multicolumn{4}{|c|}{ Identified for further review- $\mathrm{N}(\%)$} \\
\hline & Complex care & Acute care & Developmental care & Total \\
\hline & $\mathrm{N}=24$ & $N=129$ & $\mathrm{~N}=29$ & $N=182$ \\
\hline Cognitive, motor \& language milestones & $10(42)$ & $64(50)$ & $24(83)$ & $98(54)$ \\
\hline Emotional \& behavioral symptoms & $13(54)$ & $89(69)$ & $23(79)$ & $138(76)$ \\
\hline Family Questions & $9(38)$ & $22(17)$ & $18(62)$ & $49(27)$ \\
\hline
\end{tabular}

\section{Acceptability}

Feedback was collected from the first 49 of 182 families. Though interviews were intended for all but could not be conducted due to logistic concerns. Parental feedback data indicated that $71 \%(\mathrm{~N}=42)$ parents felt understanding their child's developmental progress and emotional needs was important, $65 \%$ $(\mathrm{N}=38)$ wanted to discuss the results of the form further with the paediatrician (3 parents said the decision to follow-up on the screening was up to the physician's discretion) and 61\% ( $\mathrm{N}=36)$ parents wanted further information in the form of a booklet for stimulation activities to conduct with their child, and only 1 had been to paediatric neurologist or psychologist prior to the paediatric appointment. Table 3 summarizes qualitative data from parents' feedback regarding acceptability across different domains: the content of monitoring items, overall feedback on the process and the trainee. Most parents regarded the monitoring session as "good" and many parents reportedly enjoyed thinking about and answering spouse-related questions. Some parents appreciated the increased awareness about developmental milestones and emotional needs in general.

Table 3. Parents' qualitative feedback regarding screening process 


\section{Content of the monitoring form}

"[I liked] the questions related to the spouse/partner"

"[l appreciated] the personal family questions"

"[l appreciated] Questions about the child's sleeping habits"

"[l appreciated] questions that asked whether the child is involved in fights"

"...it was good you asked about the relationship of parents with the child"

"I was surprised to know that emotions of parents play a major role in the child's life"

"I think I gained some knowledge from the questions"

"I liked the questions related to emotional changes with a new baby"

"[The questions] helped me recall important things about my child"

"The questionnaire is very comprehensive"

"The questionnaire highlighted important points that usually parents would ignore"

"I didn't know these questions were real issues"

"In the beginning we thought the questions would be irrelevant, but in the end we realized that these are important questions that will help the child in the future"

\section{The monitoring process (during the waiting)}

"It felt good to talk to you"

"It was relatable, I would like such sessions more"

"You concluded and connected the behaviour of the child with the parents"

"You connected my current situation with my wife and children, I really appreciate that"

"This would help a parent whose child is suffering"

"So many things are cleared up that we were stressed out about"

"We never noticed these things before but were happy to learn about them"

"AKUH is very interested in the development and mental health of a child"

"[it seems] the hospital is concerned about us"

"It was good, laughed a lot, made us feel good"

"This was something new related to children"

"Very useful, would want to continue such sessions in the future"

"We felt like we know our children better after this conversation"

\section{The trainee}

"It was really nice talking to you"

"Your behaviour with us was good"

"I'm satisfied after meeting you, it felt good to talk to you"

Feedback on acceptability from the physicians was shared with the ECD team via email about the families' responses on the SWYC and the feedback survey. Two paediatricians (former and current service line chief) formally responded with comments about their patients' outcomes and parental satisfaction. One physician (complex case specialist) was interested in further exploring why $50 \%$ of his screened patient population was found to be at risk for delayed milestones, with $61 \%$ at risk of developing neurotic symptoms and $75 \%$ at risk for either reason. His response to this information was, " $75 \%$ is a huge number, why do you think that is the case? Is it a selection bias - these kids are sick with chronic diseases and that is why they are at risk? Is there any correlation with complexity of disease and risk? Maybe an analysis of that will be insightful." Another physician (acute care specialist) reported, "I am happy to assist. You can continue with my outpatient and inpatient [patient population]. This is excellent and amazing data. I would suggest continuing this."

Reflections from the trainees indicated they found the process helpful for themselves aiding their counseling skills. One of them said: "I learnt a lot. Like...different milestones, items regarding autism, at same time to assess parental stress... which help us in parental counseling..." A student trainee expressed that the experience had inspired her to pursue career as a child psychologist: "I implemented my bookish knowledge in real-life scenarios which made clear that Child development is the path I would love to opt for my further studies." The student trainees were provide an opportunity to present the study findings in a departmental research event which was an additional motivating factor "I also got a chance to take part in research poster review. The experience taught me how to present and defend my findings." The significance for the families was also felt: "A quick screening like OPD screening helps us to guide parents properly, it helps us to refer children to concerned people according to the child's problem." A trainee felt the process was kind of relieving for 
families. "Screening in the OPD is challenging but it's important. We need to continue with the screening. Parents felt better when we spoke to them about their child's behaviours especially those stressed due to the child's illness."

\section{Implementation}

Practical challenges related to constrained resources and clinical referral pathways were identified over the course of the study by the trainees conducting the screening. Firstly, while all staff were cooperative, but occupied in multiple duties, they occasionally forgot to share information on study-eligible patients with the trainee for SWYC assessment. Secondly, the trainee had to carry 12 versions of printed SWYC forms and identify the correct form in a limited time period and constrained space, while conversing with waiting parents and children; identifying the correct form based on the child's age was made more difficult by parents giving vague or incorrect answers about the child's precise age. Out of all the methods that used to assess SWYC with the client's parents, it was found to be most convenient when dedicated space was available. Further suggestions and key feasibility findings for the intervention are summarized in Table 4.

Table 4. Key feasibility findings and implications

\begin{tabular}{|c|c|c|}
\hline Theme & Domain & Recommendations and Implications \\
\hline \multirow[t]{6}{*}{ Operational } & $\begin{array}{l}\text { Communication gap } \\
\text { between administrative } \\
\text { staff and developmental } \\
\text { trainee }\end{array}$ & Parents/patients can connect with the trainee at the time of registration at the clinic reception \\
\hline & $\begin{array}{l}\text { Managing paper copies of } \\
12 \text { different age-group } \\
\text { forms }\end{array}$ & \multirow{3}{*}{$\begin{array}{l}\text { An Al-powered app for use on a tablet or smartphone can be developed for auto-calculation of the patient's } \\
\text { exact age and identification of appropriate screening form in the respondent's preferred language. This app } \\
\text { can be designed for surveys/questionnaires that can be completed by the parents and by the trainee. For } \\
\text { parents with lower literacy levels, the app can include an audio option (read-out-loud the survey questions) } \\
\text { or speech to text and text to speech option. }\end{array}$} \\
\hline & $\begin{array}{l}\text { Parents had various } \\
\text { language preferences. }\end{array}$ & \\
\hline & $\begin{array}{l}\text { Some parents preferred to } \\
\text { be interviewed, while others } \\
\text { were comfortable } \\
\text { completing the SWYC } \\
\text { questions themselves. }\end{array}$ & \\
\hline & $\begin{array}{l}\text { Limited space in clinic, with } \\
\text { no toys/books/play } \\
\text { area/material available for } \\
\text { waiting children }\end{array}$ & $\begin{array}{l}\text { Dedicated space for screening and counseling with parents is required, which can also help address patient } \\
\text { privacy concerns, while providing children resources to play with while their parents are engaged in the } \\
\text { screening process. }\end{array}$ \\
\hline & Leadership buy-in & $\begin{array}{l}\text { Ensure leadership willingness for continued services. In addition, all the staff members, that includes } \\
\text { doctors, nurses and administration staff etc. should be briefed about the purpose of the QI of this } \\
\text { questionnaire for their engagement. Should also be communicated to families as a new meaningful } \\
\text { initiative. }\end{array}$ \\
\hline \multirow[t]{4}{*}{ Technical } & $\begin{array}{l}\text { Communicating news } \\
\text { about developmental risks } \\
\text { to parents, particularly } \\
\text { when parental knowledge is } \\
\text { low at the outset of } \\
\text { screening }\end{array}$ & $\begin{array}{l}\text { It was observed that parents who reported being satisfied with their child's current behaviour and } \\
\text { development were usually unaware that their child could be at risk. Parental education and counseling by } \\
\text { the paediatric consultant needs to be sensitive to parental distress that can be caused when communicating } \\
\text { results. Training for the paediatricians needs to be incorporated. }\end{array}$ \\
\hline & $\begin{array}{l}\text { Physician engagement is } \\
\text { limited due to time } \\
\text { constraints }\end{array}$ & $\begin{array}{l}\text { Structured weekly or bi-weekly meetings are required to share trends, challenges experienced and addressed } \\
\text { by physicians and the Patient Experience team and the ECD team }\end{array}$ \\
\hline & $\begin{array}{l}\text { Limited trained/qualified } \\
\text { human resource }\end{array}$ & $\begin{array}{l}\text { Dedicated staff are required to counsel and screen the parents/patients; Paediatric residents can be trained } \\
\text { in-house. Additionally, collaborations with partner universities can encourage internships for medical } \\
\text { students or psychology/allied health students to complete the screening and provide a training opportunity } \\
\text { simultaneously. }\end{array}$ \\
\hline & $\begin{array}{l}\text { Engagement of } \\
\text { stakeholders }\end{array}$ & $\begin{array}{l}\text { Ensure value-add to engage all stakeholders: parents, physicians, leadership. Regular meetings and } \\
\text { streamlined communication between paediatricians, developmental specialists and hospital administration } \\
\text { can improve referral pathways from primary to specialist care, while incorporating parental feedback into } \\
\text { these processes. }\end{array}$ \\
\hline \multirow[t]{3}{*}{ Research } & Evaluation & $\begin{array}{l}\text { Evaluation should include randomized evaluation of families waiting experience. Physician knowledge, } \\
\text { attitude and practice (KAP) and families' KAP about }\end{array}$ \\
\hline & & $\begin{array}{l}\text { ECD are another set of outcomes. Moreover, follow-up of children connecting with services can also be } \\
\text { considered. Qualitative data from parents also needs to be ensured for greater insights about the process. }\end{array}$ \\
\hline & Roll out of QII & $\begin{array}{l}\text { Start slow, ensure bottlenecks are ironed out and follow a phased roll out with different physician } \\
\text { specialties. }\end{array}$ \\
\hline
\end{tabular}

\section{Discussion}

The findings from this study indicate that developmental monitoring with support for families was largely acceptable to families, trainees and paediatricians with evidence of preliminary operational feasibility. A greater number of children indicated need for intervention for the behaviour symptoms compared to 
other domains. Another observation from the data was that parents were largely unaware about these milestones. A similar observation was found in a previous study in Pakistan [41]. These findings have implications for early intervention and support for children at risk of developmental difficulties but also for those who can benefit from general parenting advice. It also carries the opportunity to provide a vision for ECD in healthcare beyond disability [42] to optimal development through provision of nurturing care. Developmental status is indeed one of the key indicators of long-term health outcomes beyond survival [43]. Feedback from physicians suggested a need for greater understanding and discussion between ECD professionals and paediatric consultants with regards to the SWYC outcomes. The recommendation is to involve a developmental paediatrician as part of the team who also understands the health needs along with development at the technical and operational level.

Successful demonstration of feasibility lies in designing the intervention as value-add for all stakeholders. That was possible because the team spent considerable time designing the ToC laying out all opportunities and risks. Additional effort was designed for the risks. A meta-analysis of home visiting programmes to prevent child neglect and abuse found that programmes with a clear ToC with intervention components aligned to population needs had a higher chance of success [44]. The intervention had value for families and paediatricians but also psychology trainees who got an opportunity to learn and also contribute toward child health. In the long-run, hospital benefits as improved services in terms of patient and family experience [45]. Moving forward on the journey from invention to social innovation at scale should make a conscious effort to leverage partnerships between key stakeholders to achieve optimal development for children [46,47]. Effective implementation of partnerships between public and private health sectors can be achieved through a robust ToC entailing creating partnership norms, crafting collaborative work plans, regular audits and evaluation using such tools as the Partnership Assessment Tool (PAT) [48].

The strengths of the study include a cost-effective design at the outset to leverage existing resources and context-specific strengths. The trainees were interns/associate psychologists from a local psychology university seeking capacity building for clinical training. Studies from healthcare have found positive benefits of volunteers on patient experience [49]. Parental trust in paediatricians and parental perceptions regarding the credibility of AKUH as a teaching hospital were utilized to enhance feasibility. Another strength was that the study was implemented as part of an on-going patient and family-centric initiative emphasizing compassionate care. This allowed for a quick buy-in of the physicians whereby they were aware of the elements of psychosocial care and effect on health outcomes. A limitation of the study is that the SWYC is not validated for the Pakistani population. However, the SWYC was intended to be used as an indicator of need for parental conversation by the paediatrician. In case of due concerns, children and their parents were then referred to developmental specialists. A study using SWYC in Brazilian context found similar performance of children between birth to 36 months as North American children [50]. Moreover, the authors felt given the scale of the problem, this limitation of validated tools in the Pakistani context should not be a barrier to initiation of developmental monitoring processes. An additional limitation is that for the purpose of this study, we were not able to follow up with parents and children to collect data on how many referred/identified at-risk children went on to connect with specialist services for additional support and if there was any agreement on the clinician diagnosis and screening results. It was not possible for the research team to follow-up with the physicians to understand how the results were discussed with the families and if they developed distress. Given paediatricians have an on-going relationship with families, we assume that may have mitigated some of the risks. Another limitation is that we could interview only 49 families. Further evaluation is required to test the model with adequate resources.

\section{Conclusion}

When designing implementation models for developmental monitoring, the context needs to be carefully considered for feasibility. Due time and effort should be invested to understand how the intervention would operate but also how it would lead to a behaviour change.

\section{Abbreviations}

- AKUH - Aga Khan University Hospital, Pakistan

- ECD - Early childhood development

- LMIC - Low to middle income country

- QI-Quality Improvement

- SWYC - Survey for Wellbeing of Young Children

- ToC - Theory of change model

- WHO - World Health Organization

\section{Declarations}

\section{Acknowledgements}

The authors would like to thank the children and their parents who enrolled and participated in the developmental screening and counseling session, as well as the Paediatrics consultants who participated in this pilot quality improvement project, Ms Maira Niaz for her support in data collection and weekly reporting, and the Paediatrics out-patient clinical staff who facilitated data collection processes for the developmental team.

\section{Ethics approval and consent to participate}


The study was conducted in accordance with the Aga Khan University guidelines and regulations. The study was approved as an exemption being a Quality Improvement project by the AKU Ethics Review Committee (ERC \# 2020-5654-14776). As part of

the institutional regulations (AKU ERC), an exemption does not require consent for participation. As per the policy, Exemption clause 3 identifies, "Research involving benign behavioral interventions in conjunction with the collection of information from an adult subject through verbal or written responses (including data entry) or audiovisual recording if the subject prospectively agrees to the intervention and information collection." The parents of the patients were briefed about the purpose of the survey and verbal consent was obtained prior to data collection.

\section{Consent for publication}

Not applicable

\section{Availability of data and materials}

Data will be made available upon request to the corresponding author.

\section{Competing Interests}

The authors have no competing interests to declare.

\section{Funding}

No funding for data collection, analysis, interpretation, or manuscript-writing was available for the study.

\section{Author Contributions}

MR (then-director of Patient Experience) conceptualized and designed the study, trained volunteer psychologists to implement the intervention in the outpatient clinic, prepared analysis plan and led the writing of the manuscript draft. WM analyzed and interpreted the study findings and contributed to the manuscript draft. KN contributed to the analysis of family experience data and contributed with reflections on her experiences as an assessor in this program. $\mathrm{BH}$ provided intellectual input towards the study design in his capacity as Paediatrics service line chief and to the manuscript draft.

\section{References}

[1]. Black MM, Walker SP, Fernald LC, et al. Early childhood development coming of age: science through the life course. The Lancet. 201701 7;389(10064):77-90.

[2]. Ertem IO. Developmental difficulties in early childhood: prevention, early identification, assessment and intervention in low-and middle-income countries: A Rev. 2012. WHO.

[3]. Shahshahani S, Vameghi R, Sajedi F, et al. Comparing the results of developmental screening of 4 to 60 -month-old children in Tehran using parents' evaluation of developmental status and ages and stages questionnaires. Iran J of Paediatr. 2017 Apr 1;27(2). DOI: 10.5812/ijp.6179.

[4]. Morrison J, Chunsuwan I, Bunnag P, et al. Thailand's national universal developmental screening programme for young children: action research for improved follow-up. BMJ Glob Health. 2018: 3:e000589. http://dx.doi.org/10.1136/bmjgh-2017-000589

[5]. Lipkin PH, Macias MM. Promoting optimal development: identifying infants and young children with developmental disorders through developmental surveillance and screening. Paediatr. 2020 Jan 1;145(1).

[6]. World Health Organization. Monitoring children's development in primary care services: moving from a focus on child deficits to family-centred participatory support: Report of a virtual technical meeting. 202006 09. https://apps.who.int/iris/bitstream/handle/10665/335832/9789240012479-eng.pdf

[7]. Britto PR, Lye SJ, Proulx K, et al. Nurturing care: promoting early childhood development. The Lancet. 2017 Jan 7;389(10064):91-102. https://doi.org/10.1016/S0140-6736(16)31390-3

[8]. WHO, The World Bank and UNICEF. Early Childhood Development. Nurturing Care. 2019. https://nurturing-care.org/wpcontent/uploads/2019/09/Pakistan.pdf

[9]. Nores M, Fernandez C. Building capacity in health and education systems to deliver interventions that strengthen early child development. Ann of the NY Acad of Sci. 2018;1419(1):57-73. DOI: 10.1111/nyas.13682

[10]. Shabbir A., Malik S. A., Malik S. A., et al. Measuring patients' healthcare service quality perceptions, satisfaction, and loyalty in public and private sector hospitals in Pakistan. Int J of Quality \& Reliab Manag. 2016;33(5). https://doi.org/10.1108/IJQRM-06-2014-0074

Page $11 / 14$ 
[11]. World Health Organization. Nurturing care for early childhood development: a framework for helping children survive and thrive to transform health and human potential. https://apps.who.int/iris/bitstream/handle/10665/272603/9789241514064-eng.pdf

[12]. World Health Organization. World Health Statistics 2015. WHO; 2015; Available at:

http://apps.who.int/iris/bitstream/10665/170250/1/9789240694439_eng.pdf

[13]. Hafeez M. Poor Healthcare in Pakistan. Harv Int Rev. 2014 Apr 1;35(4):52-56. Accessed from https://search.proquest.com/docview/1652372795? accountid $=135034$

[14]. Khoumbati K, Abbasi M, Shah SG, et al. Integration of public sector healthcare information systems with private sector healthcare providers in Pakistan: challenges, opportunities, and solutions. In Emerging Markets from a Multidisciplinary Perspective 2018 (pp. 233-240). Springer, Cham.

[15]. Khan MA, Owais SS, Ishaq S, et al. Process evaluation of integrated early child development care at private clinics in poor urban Pakistan: a mixed methods study. BJGP open. 2017 Oct 1;1(3). https://doi.org/10.3399/bjgpopen17X101073

[16]. Pandey S, Menezes R, Ganeti S. Why Indian nonprofits are experts at scaling up. Stanford Social Innovation Review, Spring. 2017:17-23. Accessed from https://ssir.org/articles/entry/why_indian_nonprofits_are_experts_at_scaling_up

[17]. Davis S. \& Gibbons E. A portfolio approach to social innovation partnerships. Stanford Social Innovation Review. 2017. Retrieved from https://ssir.org/articles/entry/a_portfolio_approach_to_social_innovation_partnerships\#

[18]. Seward N, Hanlon C, Murdoch J, et al. Contextual equipoise: a novel concept to inform ethical implications for implementation research in low-income and middle-income countries. BMJ Glob Health. 2020 12 1;5(12):e003456.

[19]. Breuer E, Lee L, De Silva M, et al. Using theory of change to design and evaluate public health interventions: a systematic review. Implement Sci. 2015 12 1;11(1):63.

[20]. Azeem MW, Dogar IA, Shah S, Cheema MA, Asmat A, Akbar M, Kousar S, Haider II. Anxiety and Depression among Parents of Children with Intellectual Disability in Pakistan. J Can Acad Child Adolesc Psychiatry. 2013 Nov;22(4):290-5. PMID: 24223048; PMCID: PMC3825469.

[21]. Rathore, F. A., New, P. W., \& Iftikhar, A. A report on disability and rehabilitation medicine in Pakistan: past, present, and future directions. Archives of physical medicine and rehabilitation. 2011; 92(1), 161-166. DOI: 10.1016/j.apmr.2010.10.004

[22]. Khan F, Amatya B, Sayed TM, Butt AW, Jamil K, Iqbal W, Elmalik A, Rathore FA, Abbott G. World Health Organization Global Disability Action Plan 20142021: Challenges and Perspectives for Physical Medicine and Rehabilitation in Pakistan. Journal of rehabilitation medicine. 2017 Jan 5;49(1):10-21. DOI: https://doi.org/10.2340/16501977-2149

[23]. Lancaster, G.A., Thabane, L. Guidelines for reporting non-randomised pilot and feasibility studies. BMC Pilot Feasibility Studies 5, 114. 2019. https://doi.org/10.1186/s40814-019-0499-1

[24]. Portela MC, Pronovost PJ, Woodcock T, et al. How to study improvement interventions: a brief overview of possible study types. BMJ Quality \& Saf. 2015 May 1;24(5):325-36.

[25]. Arshad A, Lalani N, Sultan N, et al. How to improve patient experience of compassion through nursing: Development of an on-job mentorship programme in a tertiary care hospital, Pakistan. 2020. DOI.10.21203/rs.3.rs-122995/v. 1

[26]. Rathore FA, Mansoor SN. Developmental milestones: Even the Physicians don't know enough and what we need to do. J Pak Med Assoc. 2013 Jan 1;63:132-3.

[27]. Hamdani SU, Huma ZE, Wissow L, et al. Measuring functional disability in children with developmental disorders in low-resource settings: validation of Developmental Disorders-Children Disability Assessment Schedule (DD-CDAS) in rural Pakistan. Glob Ment Health. 2020;7.

[28]. Black MM, Dewey KG. Promoting equity through integrated early child development and nutrition interventions. Ann NY Acad Sci. 2014; 1308(1):1-10

[29]. Hussain AS, Ali SR, Ariff S, et al. A protocol for quality improvement programme to reduce central line-associated bloodstream infections in NICU of lowand middle-income country. BMJ Paediatr. Open. 2017;1(1).

[30]. Torpie K. Customer service vs. patient care. Patient Exp J. 2014;1(2):6-8. DOI: 10.35680/2372-0247.1045

[31]. Kaplan GS. Health care scheduling and access: a report from the IOM. JAMA. 2015 Oct 13;314(14):1449-50. DOI: 10.1001/jama.2015.9431

[32]. Al-Yateem N, Brenner M, Shorrab AA, et al. Play distraction versus pharmacological treatment to reduce anxiety levels in children undergoing day surgery: a randomized controlled non-inferiority trial. Child: Care, Health and Dev. 2016 Jul;42(4):572-81. https://doi.org/10.1111/cch.12343

[33]. Servati T, Pethe K, Tiase V. Does the use of volunteers and playbooks in pediatric primary care clinic waiting rooms influence patient experience? Patient Exp J. 2019;6(1):127-33. DOI: 10.35680/2372-0247.1329 
[34]. Chang SM, Grantham-McGregor SM, Powell CA, et al. Integrating a parenting intervention with routine primary health care: a cluster randomized trial. Pediatr. 2015 Aug 1;136(2):272-80.

[35]. Wolf JA. Patient experience: the new heart of healthcare leadership. Front of Health Serv Manag. 2017 Apr 1;33(3):3-16.

[36]. Perrin EC, Sheldrick RC, Visco Z, et al. The survey of well-being of young children (SWYC) user's manual. Boston, MA: Floating Hospital for Children at Tufts Medical Center. 2016.

[37]. Lucas JE, Richter LM, Daelmans B. Care for Child Development: an intervention in support of responsive caregiving and early child development. Child: Care, Health and Dev. 2018 Jan;44(1):41-9.

[38]. Rasheed M, Bharuchi V, Mughis W, et al. Development and feasibility testing of a play-based psychosocial intervention for reduced patient stress in a paediatric care setting: experiences from Pakistan. DOI:10.21203/rs.3.rs-88217/v1

[39]. Bowen DJ, Kreuter M, Spring B, et al. How we design feasibility studies. Am J of Prev Med. 2009 05 01;36(5):452-7.

[40]. Burnard P, Gill P, Stewart K, et al. Analysing and presenting qualitative data. Br Dent J. 2008;204(8):429-32.

[41]. Mushtaq A, Rehman A. Developmental milestones: Do the parents know enough? J Pak Med Assoc. 2012; 62: 991.

[42]. Stein RE. Are we on the right track? Examining the role of developmental behavioral pediatrics. Pediatr. 2015 04 01;135(4):589-91.

[43]. Kelley, T.A. International Consortium for Health Outcomes Measurement (ICHOM). Trials 16, 04 (2015). https://doi.org/10.1186/1745-6215-16-S3-04

[44]. Segal L, Sara Opie R, Dalziel KI. Theory! The missing link in understanding the performance of neonate/infant home-visiting programs to prevent child maltreatment: A systematic review. The Milbank Q. 2012 03;90(1):47-106.

[45]. Porter ME. What is value in health care? N Engl J of Med. 2010 Dec 23;363(26):2477-81. DOI: 10.1056/NEJMp1011024

[46]. Strengthening Nonprofits. Partnerships: Frameworks for Working Together. 2017. Accessed from http://upwardspirals.net/wpcontent/uploads/2015/01/Partnerships-Frameworks-for-Working-Together-Capacity-Building-Library.pdf

[47]. Buse, K., \& Tanaka, S. (2011). Global Public-Private Health Partnerships: lessons learned from ten years of experience and evaluation. Int Dent J. 61, 210.

[48]. Hardy B, Hudson B, Waddington E. Assessing strategic partnership: The partnership assessment tool. London, UK: Office of the Deputy Prime Minister; 2003. Accessed from

https://www.researchgate.net/profile/Bob_Hudson2/publication/265039661_Assessing_Strategic_Partnership_The_Partnership_Assessment_Tool/links/54aa:

[49]. Lorhan S, van der Westhuizen M, Gossmann S. The role of volunteers at an outpatient cancer center: how do volunteers enhance the patient experience?. Support Care in Cancer. 2015 Jun 1;23(6):1597-605. https://doi.org/10.1007/s00520-014-2505-8

[50]. Moreira RS, Magalhães LC, Siqueira CM, et al. "Survey of Wellbeing of Young Children (SWYC)": how does it fit for screen. developmental delay in Brazilian children aged 4 to 58 months?. Res in Dev Disabil. 2018 Jul 1;78:78-88.

\section{Figures}




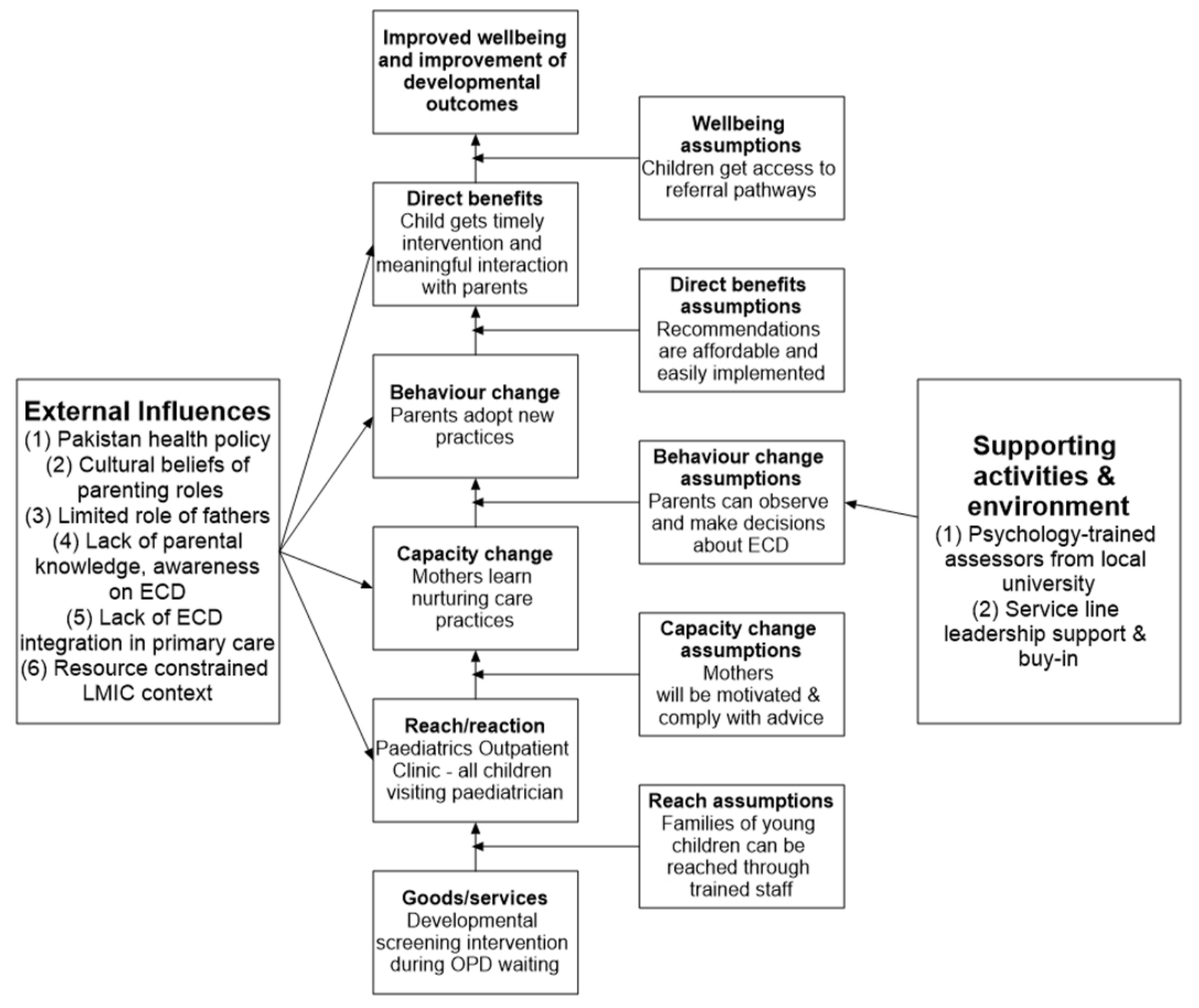

Figure 1

Theory of change model for integration of family-centered developmental monitoring into primary care

\section{Supplementary Files}

This is a list of supplementary files associated with this preprint. Click to download.

- StaRIchecklistforauthorcompletion.docx 